\title{
Visual Narratives: Image and Consciousness of Social Reality
}

\author{
Christine Wagner \\ ORCID: 00oo-0002-3445-1446• ResearcherID: T-9766-2017 \\ UNICAMP, Institute of Arts, São Paulo
}

Received 31 October 2017 - Revised 20 November $2017 \cdot$ Accepted 22 November 2017

Abstract

This article concerns images that portray a social reality in relation to the ability that humans have to create narratives that are a configuration of the collective consciousness. According to arguments developed in the literature and broadcasted by the media, citizens' actions guard both the public space and the configuration of culture. The images associated with relevant issues determine the public's responses and give more power to public opinion. However, the results of innovation depend on the political will at any given time. According to Jürgen Habermas, the rationality of the discourse of decision makers guides the collective conscience through their communicative actions. In this sense, the message and its ideology can effect changes by capitalizing on belief in the narratives. Therefore, the main goal is to understand social reality in relation to the influence of visual narratives.

Keywords: illusion, determination, media, transformation, cultures.

\section{Introduction}

Cultures are a presence, an influence, and the heritage of humanity. This legacy can be universal or restricted to a small community. At the same time, a variation of cultures can be considered within the dynamic of a global metropolis, which maintains a part of its heritage together with a universal culture. The subsequent complexities of the development make possible the integration of individuals into their diverse cultures. This dynamic is influenced by the narratives through which the individual acquires a presence, because these narratives transmit tradition, education and knowledge of the language, history, art, and costumes. The process of acculturation through intellectual, ethical, and aesthetic development, whether among the nations or between different nationalities concentrated in the same country, results in a diversity of the cultures. A prominent characteristic of the results can be seen in the artistic practices of the present, on the works that remain in time, marking not only a cultural origin but also a process of identification and adaptation to other realities in time and space.

It is not always easy to distinguish the ideas of a necessary future from historical human achievements in the course of intellectual, ethical, and aesthetic development. The historical presence in the sense of human self-development is also an ongoing and connected process in global metropolises. Also, the metropolis imposes a rhythm on the world under the directives of its hegemonic powers, on their cultural productions, which impacts the progress and

(C) Authors. Terms and conditions of Creative Commons Attribution 4.0 International (CC BY 4.0) apply. Correspondence: Christiane Wagner, Rua Theodor Herzl, 49 ap. 51, Sao Paulo - 05014-020, Brazil. Email: christiane.wagner@malix.univ-paris1.fr. 
the development of civilization. Undoubtedly, the conditions and contexts are necessary for interpretations and general laws of historical development.

- The primary goal is to analyze communicative actions and collective conscience through visual narratives.

- This leads to the understanding of the socio-historical influence and its political representations in art and literature.

- This is a way of analyzing media and consciousness as illusions.

- Think about artifices and inventions in visual culture.

The knowledge and experiences of each person with respect to the particular conditions of one's life - which shape one's subjectivity - present the "truth" as part of life, that is, as an interpreted form of the world, absorbed and shared in one's cultural milieu. There is an exchange of values in a continuously processed social relation, in which the individual has a partial view of the world. Each new message renews knowledge and experiences, and imparts new values. The message is generated for political and economic reasons, structuring the culture. Thus all aspects of culture can be seen as communication processes and acquired experience, while the new elements of invention and artifice acquire meaning through ideology. For Umberto Eco, ideology is a message that starts with a factual description and a testing of its theoretical justification, and is gradually adopted by society as an element of its code. As soon as the message is used as ideology, it becomes one of the worldviews that, as a "reality" shared by several individuals, is disseminated among a large proportion society, according to the material circumstances of life. Ideology, then, is seen as a motivating element of modern society and as an image of progress. This image convinces the investors and producers in the technology industry to sponsor the significant evolution of our imaginary world. The term "evolution" directs the meaning and the formation of the thought of humanity, which believes in the possibility of overcoming a state, in the sense of change as a latent desire for modernization.

Language, as a form of expression and narrative, is continually modified by the external world, which conditions the emergence of a set of statements that are formed by a set of signs that are made available to society. It is the individual in transformation with his techniques, obtaining tools, and, with his language, receiving symbolic value. It is the significance that qualifies a regime that leads to the illusion. That is one of the basic characteristics of the human being: the ability to formulate abstractions from everything in the world, in the search for a cause, or in the process of distinguishing truth and reality. Relative or absolute? So many other questions derive from abstraction in the constant search for answers that are always conditioned to a model, a representation to be understood.

The dichotomy of the imaginary worldview and the real world is imbued with all its positive and negative aspects. The constant creation, the "recreation", through inventions and artifices, is the link in this current and there will always be a new message that will maintain the continuous relationship of our existence as a communication process throughout our lives and those of future generations. In short, the broad idea is not the infinity of "recreation" to be realized, but always the continuity of the production of our simulated and dissimulated messages. Such messages offer meaning to our ways of life; the growth of possibilities, which are summarized in a single sense, is not the argument, but the invention and the artifice. Moreover, many visual productions are created for the public that convey an imaginary universe and therefore represent the totality, such as environments, scenarios, and other fantasy worlds, as well as installations, works of art, sculptures, and monuments in the everyday reality of urban centers. Examples include interventions of virtual objects that can be introduced into real environments and "augmented reality", which also provides the individual with the opportunity to handle these objects, enabling interaction with the environment. However, to be part of the real environment, virtual objects are made using engineering software and appropriate technological 
devices for augmented reality. Although most of the devices used in a virtual reality environment can be used in augmented reality environments, there are cases in which some adaptations are necessary due to the differences between technological devices. The direct optical vision system uses glasses or helmets with lenses that allow for the direct reception of the actual image while enabling the projection of virtual images properly adjusted to the real scene.

It is also necessary to understand the process of creating products that are designed in an imaginary world that is different from the creative experience of the artist, intercalating fantasy and imagination to represent reality. One must also consider the invention of simulacra to feed the imagination through creativity, or even from science fiction, when designing an imaginary future. Perhaps it is the experience of new technologies that enables the simulation of the new experience, stimulating creative projects.

\section{Idea, form, and self-consciousness}

In the 1820 , modernization was changing daily life, especially in the most prominent cities of that period, when Hegel was studying the spirit of the times in Berlin, Vienna, and Paris. Such experience had a significant influence on his philosophical reflection on art in relation to the social context through which he perceived the tendencies of modern times and artistic production. Hegel perceived that the growing assertion of artistic freedom and the autonomy of aesthetics within art resulted in an unlimited autonomy of individual choices. Hegel's aesthetics are part of his philosophy of spirit (Houlgate, 2016), which is detailed in his work Phenomenology of Spirit (1807). In Hegel's philosophy of art, it comes to be valued according to its characteristics, in particular its form and content, and also specific criteria determined by the context, ideas, and place in history, in which art production is an attempt to reflect social and political reality. Following this line of thought, Stephen Houlgate (2016) explains: "[...] Hegel is well aware that art can perform various functions: it can teach, edify, provoke, adorn, and so on. His concern, however, is to identify art's proper and most distinctive function. This, he claims, is to give intuitive, sensuous expression to the freedom of spirit. The point of art, therefore, is not to be 'realistic' - to imitate or mirror the contingencies of everyday life - but to show us what divine and human freedom look like. Such sensuous expression of spiritual freedom is what Hegel calls the 'Ideal,' or true beauty".

The individual, through his reason (self-determination), acquires more freedom, that is, he is conscious of his autonomy over his decisions; it is the exercise of one's thoughts, of one's consciousness of life - spirit (Geist). One's subjectivity finds space to experience itself through language and thoughts while the person experiences his autonomy materializing. In art, this relation to the spirit - the Idea - concerns the content of art and its mode of presentation, which is formed materially. Thus, the balance between content and form, i.e., a synthesis achieved through a process of dialectical thinking, in which the spirit clarifies the confrontation between thesis and antithesis, is related to a moment in time and place of realization. For Hegel, the work of art reaches its highest level of achievement by the expression of the balance between content and form, technique and materials, in each epoch and state of consciousness of life, that is, the spirit of the time (Zeitgeist). In this realization, the artist's imagination exerts its potential and presents the characteristics of socio-historical influence and its artistic representations.

On the one hand, Hegel argues that Greek sculpture concretizes the highest level of evolution as pure beauty realizing its spiritual freedom as self-consciousness of life and, because of this, classical art has, until Hegel, inspired a large Western audience. On the other hand, Hegel's aesthetic is critiqued in Marx's work (Thom, 2014). With some subtleties to be considered, which shape another perception. Marx adequately demonstrated that the evolution of art does not depend on the consciousness of the spirit. For Marx, human evolution is primarily determined by material, social, and economic conditions. He pointed out that the ancient forms of artistic 
expression linked to archaic societies still thrilled modern society in his day. However, this expression would be the product of education that would keep the aesthetic and cultural criteria preserved and transmitted by tradition. Whatever we perceive the reason to be for the fact that permanence could be attributed to these classical works throughout history, the fact is that such classical works can still evoke emotions. The themes in the ancient tragedies and also represented in sculptures are eternal, such as survival, fate, destiny, passion, despair, death, and love. All sentimental matters are timeless and trans-historical, and are detached from the material conditions of production and economic oppression. Even if these conditions are also responsible for our emotional states, there will always be an emotional state for any fundamental experience of human relations, regardless of the dominant material factors that might influence one in every season and place.

Only a small portion of Marx's theory (1867) is dedicated to the theme of art. Nevertheless, throughout the 2oth century significant transformations occurred that were based on interpretations of Marx's work. His arguments about capitalism and the interpretation of it influenced a large part of the world's population and became political ideals, placing art in a position of submission to political ideologies as the consciousness of life. Consequently, a Marxist aesthetic was integrated into numerous theories that sustained the artistic world during the 2oth century, whether its practitioners were for or against the dominant ideologies, and which established the relationship between art, society, and politics. Along the lines of a Marxist aesthetic, and following Hegelian thought, is the theory of Hungarian philosopher György Lukács (1885-1971), for whom art was a "reflection of reality", as he wrote in History and Class Consciousness (1923). This results from the interaction between humanity and nature, work, and society, which are essential elements of the act of creation. Thus the historic moment would have great importance not only at the time of creation but also in terms of the aesthetic conception of a work. Thus, Lukács considered art to be the most appropriate form of expression of a selfconsciousness of humanity, or "self-consciousness of the human race". Lukács, however, was unaware of the artistic and political significance of modern art. Therefore he did not realize that the modernist movements, notwithstanding their formal, experimental characteristics, also sought, as he did, to bring art closer to reality, which it denounced and criticized. In other words, it increased sensitivity in order to perceive the entrance of the modern human into a disenchanted and inhuman world.

We try to understand the essential concepts and contexts that were important during the artistic or technical production. We are based, in a generalized way, from ancient Greece to the socio-historical direction of the West, in a universe of artistic achievements related to social reality. Thus, in a chronology of ruptures, retakes of values, movements, wars, revolutions, and innovations, we see humans imagining freedom and "happiness", and believing in the life of "truth" as the consciousness of human existence. However, to understand all interpretations is mainly to comprehend and accept that new interpretations are still possible and that the world is not another, but the same, in its constant evolution.

To understand the context of the arts and the ideological dynamics of images in relation to contemporary social reality, we can embrace a theory related to the mode of production exercised by a globalized society, such as in Technology and science as ideology (Technik und Wissenschaft als Ideologie) by Habermas (1968). Understanding society and also the nature of its actions is part of a complex process that includes the development of techniques, and the art of creating and producing. In the course of their history, literary and artistic achievements have transformed the way we understand them. Aside from the significance of metropolitan life, we analyze technical evolution and scientific status, and its contribution to raising art and its creators to a position of great importance. However, to the same degree, its trivialization in the context of subjective values - based on aesthetic judgments that are subject to polysemy - is, above all, in the face of an immense diversity of values, the orientation of artistic speculations that form the 
collective consciousness. The transformation of reality in society, from ancient Greece to contemporary culture, offers us an image of an immense inventory of all the human achievements as the presence, influence, and heritage of humanity.

Therefore, in general, what constitutes the configuration of a contemporary image in its search for the consciousness of social reality is to understand that the dynamics of the global metropolises, in their process of transformation, always seeks to meet the needs of the modus vivendi, not only by the means mentioned before, which would lead to other reflections on the constant artistic movements. However, the modifications of the system and market, and the relations of production, new objects and services are, nevertheless, the consequence of globalization and standardization in the configuration of a single image of reality. Such an image is the representation of a standard, collective consciousness. Art is facing technological and scientific evolution in a scenario of contemporary universality that is not found only in social transformation, but especially in the environment. Despite the fact that language has evolved and arrived at the writing stage, the capacity for perfect communication is still lacking. If we consider the differences in intelligence, knowledge, and social domination, and especially the different languages, pictorial language continues to unify the communication of different cultures, accompanying the new forms of representation. The new technologies offer new possibilities, regardless of any similarity with the established image.

Still, under the effects of modernity, Pierre Francastel (1956) situates us in evolution using a temporal example of the rhythm of life that represents French society. He mentions that Victor Hugo, in 1850, said that the world traveled on a wagon and spoke French, and that, in 1950, the author himself said in his work that the world would fly by plane and would design and sculpt as in Paris. Today, however, we would say that the world has become deterritorialized and we cannot identify the time or even the space. Morin (2007) asks: "Where does the world go?" (Où va le monde?). Apparently, the aim of this is to configure the contemporary image in its visual narratives and the consciousness of social reality.

\section{Illusion and consciousness}

According to analytic philosophy, we are conditioned by the vicissitudes of language, tradition, and the history of Western thought. Situating ourselves in a socio-cultural system, therefore, is necessary in order to understand images as a means of communication. Likewise, idealists developed systems and theories to study the phenomena of consciousness - to learn about the apparent manifestations of the spirit - in terms of Hegel's approach to reality as a historical process. In Hegelian philosophy, the spirit is in a historical process, the purpose of which is development and evolution. Thus, we will approach the concept of collective consciousness in light of some of the observations of Habermas on contemporary contexts of development.

In his work The structural transformation of the public sphere, Habermas (1962) presents a discussion about the assumption that a society is developed by its common interests, through media, the judicial system, and the state's political power. The author discusses questions about civil rights relating to the liberty of expression, females' equal participation with men, and, finally, the appropriation of this space in common with other individuals for the possible involvement and achievement of all. By systematizing public dynamics in its complex grandeur, Habermas demonstrates the formation of a collective consciousness that results from rational agreement within social relations. Actions are performed in the public space and consensus is sought as an indication of success. Habermas presents a rational notion of social reality. He discusses the process of modern state development in relation to the private sphere when the latter becomes public, and in which public opinion builds the public sphere. 
The greatest reference in the 18th century to a public and politicized life was the French Revolution, not only for France, but also for Germany, as confirmed by Habermas and also, of course, for the whole of Europe and a significant part of the world. Literature and the arts have come to be conceived as contributions to political discussions or allusions to political events. The greatest focus, however, is not on the aspects of urbanization or the ideologies of the generation that marked the cultural revolution, nor on the consequences of economic and social development. It is not even on the characterization of the process of transformation due to the emergence of new policies and commercial relations that guide the market system. Rather, the emphasis is on the analysis of the consolidation, by consensus, of the orientation and meaning of society, and in particular the influence from the 18th and 19th centuries, when literature became more important to the bourgeoisie, giving meaning to mass culture. Our illusion of reality is due to the influence exerted by art and literature, as well as by technological resources, which build the mass culture through the media. Accordingly, the public sphere has been configured by all these influences. Thus, society is conditioned to adapt to transformed models through a process that sustains itself, without significant risks and without considerable controversy. However, if the extremes were compared over time, the differences would be noticeable. Therefore, these differences bring changes independently of a desire to innovate. Thus, cultural transformations and models are both the results of decisions and due to a process of continuity of values through confirmation, i.e., the establishment of the consciousness of social reality. The importance of this process is not only its origin but also its implementation, with errors and corrections throughout the experience. Of course, for aggregation between individuals in social reality, life depends on ethics. Without them, life could not continue in society, decisions would not be the result of common agreements, and the models would not serve the common good. However, the question of innovation in this context seems unlikely. Man would find innovation only in the breaking of their relationships within models, resulting in paradigm changes. It is understood that models, as with all presupposed relationships, are pre-established with the intention of concretizing a "standard assumption of relations" so that the public space forms the collective consciousness. However, there is always room for improvement.

Society is continuing to be presented with a growth of media power, while the search for a balance between the liberty of expression and equality of rights remains. Such a significant complexity of needs in a contemporary democracy can also be seen in competitive challenges regarding a common agreement, resulting in a collective consciousness. There are many institutions, communities, and associations nowadays that have interests in common with many others. Among the many interests, the most detached are cultural events. For this reason, the state has been subsidizing arts and educational initiatives such as museum exhibitions, concerts, festivals, etc., instead of the previous subversive achievements that prevailed in modernity. Moreover, there is a relationship of exchange; that is, a public relationship with common goals and an agreement to attend to the models of a society's interests (Habermas, 1981).

Among the achievements and appropriation of space, the image is constructed by the collective consciousness. Besides, a danger that threatens human existence comes in the shape of collective consciousness and draws up the argument of necessity, and also stimulates the search for solutions through new creations and discoveries. The merits of the discoveries, also considered innovations, can be found in the evolution of technology. However, society proposes a new scenario for the solutions of a fourth generation, which is already claiming its rights, such as the controversial nanotechnology.

According to The principles of philosophy of Descartes (1640), consciousness in its operation is conditioned to error, mistake, and illusion. Therefore, the Cartesian doubt will be related to the fact that consciousness affirms itself when it finds itself in situations of mistakes and errors; that is, it is always seeking an affirmation to deal with everything that is not confirmed as true. This possibility of truth as theory, based on the thought of Descartes and Spinoza, is 
understood as an affirmation of freedom via knowledge of the truth. In this way, we consider free will to be a power of freedom, which would not be possible without knowledge of the decision, facilitating a consideration of the criteria of truth and error in the practical affirmation, especially by technique and science. The phenomenon of illusion is characteristic of consciousness, which, according to Spinoza, is no more than imagination, which, for the consciousness to be free, would be the consciousness that there is no reality.

Thus the truth is the subject that seeks the understanding of this determinism, which would lead to the discovery of a new freedom, which would be the understanding of what determines us. According to Spinoza, it is a necessity of our nature to know what our essence is and what determines us, whether internal or external causes. For him these are limitations that cause a human being to make mistakes. Therefore, for a consciousness of freedom, it is necessary to understand the conditions of human nature. Thus, truth consists of being free, knowing oneself, and knowing the outer things that are in contact with the truth, with the truth offering the power to be free. It is this freedom that is defined by the understanding of knowledge; it is the relationship between the understanding and the will. This relation is seen by Descartes, and also, represented by Spinoza. This knowledge consists of the understanding of the primary questions. In the thought of Descartes, this means that to be free is to know the truth. It shows us that free will is an illusion; it is a freedom that is no longer a choice. We are encouraged to choose that which seems to be the truth and the best; this stimulus that we have for the truth is due to the inclination we have for the truth because we would have no other thing.

The moment that one views freedom as an illusion, one would be in true freedom; in short, we must know freedom, not truth. The consciousness of the experience of freedom places one in a condition of recognition, then of a consciousness of the possibility of choosing one option or another, and one will wonder about the arbitration and reality of this arbitration, i.e., in general, all the difficulty of the subject is a paradox. Thus, we will try to overcome the contradiction, and thus the paradox. The experience that I have with my freedom is an experience of consciousness, and consciousness is an illusory phenomenon by which the fact of choice is consciousness, according to Spinoza. Thus, the fact of choosing, of having the experience of consciousness, is already being free.

However, the freedom we approach in the arts is one in which the artist is conscious and in full control of the boundaries and rules of creating. It is an achievement within the limits of creation, regardless of the historical context and, of course, the idea of freedom bound to that moment. The artist recognizes the limits that exist in any realization, that is, the problems that seek solutions, thus requiring that the artist can always solve them. However, through creativity, we can well understand that artistic practice is always linked to the technique and methodology of achievement of the form, the rules of art, which necessitates idealizing freedom. Creations formed without any rules or limits were never an accomplishment. Somehow they always existed to be overcome or transgressed, only for other rules or limits to be imposed - for either subjective or objective reasons - as a manifestation of freedom as well as the autonomy of the artists. Therefore, rules are compatible with freedom, confirming that freedom is exercised through the power of rules because there are edicts that arise from a subjective need to confront some problems or difficulties. Ultimately, the needs to be met require the will to perform.

The freedom lies in the creation of artwork, not in the sense of liberty as a theme, but in terms of the rules within the meaning of autonomy and the means by which we produce for a determined purpose. Thus, we find ourselves, throughout history, in the Aristotelian sense, with work that is not created from anything, but from something, with the determined purpose of forming creation. Then we perceive that we have two needs for freedom: one is subjective, an internal necessity in the sense of liberty idealized in the Platonic sense; and another more objective, which is a need imposed by the medium, by the socio-cultural context, in the meaning of a poetic freedom influenced by the ideas of Aristotle. On the whole, there are many theories 
about consciousness to explain the human condition in the relation to oneself and one's ambiance. Different ways of thought have been developed about this phenomenon and its diversity of features. As Robert Van Gulick (2017) puts it, "each in their own way aims respectively to explain the physical, neural, cognitive, functional, representational, and higher-order aspects of consciousness".

\section{The artifices of innovation and collective consciousness}

Now, in the 21st century, humanity presents itself in its cultural diversity as a planetary reality under the tutelage of technology and communication. It is in continuity, however, with the need for the creation of illusion, which so many other artistic achievements have made possible. The notion that illusion is important is a matter of divided opinion. However, we do not know in experience the importance of not having it. We need only think of Plato's ideas, evaluating art in relation to the truth and Plato's influence on the Western mindset. However, artists always form a reality. Even the art would offer that illusion.

In the current planetary crisis, Edgar Morin says that many people might believe that if they lose their illusions, they will lose everything; however, this is a mistake. In Morin's view, we would attain a huge achievement if we lost our mistakes, that is, the consciousness necessary to decide on our future. Therefore, in the Cartesian sense, knowledge through errors and corrections are possibilities of the consciousness as illusions.

However, Morin thinks about the loss of faith in the context of the idea of progress, and consequently that the loss of this principle would also be progress, by discovering that progress is a myth. Therefore, social progress is a system of values that operates through instability and insecurity and seeks security by setting optimistic forecasts. We can see this dynamic in social, cultural, economic, and political contexts. Furthermore, the image of success consists of innovation as self-consciousness. Thus, it is possible for the individual to select information, but the media continues to have the capacity to construct a social reality.

The media and social networks converge to report on recent and significant events, which comprise a global social reality. Moreover, news and images present illusions as reality through this technological convergence. The users of communication technologies, which are always in gradual evolution, seek not only technical perfection or the overcoming of humans by the human, but also identification and signification as a form of better interaction and the illusion of reality. This sense of overcoming of humans by the human means a consciousness of perfection as the illusion.

However, this question remains: How can one innovate? (Wagner, 2014) In recent times, innovation has been considered extremely important in all fields of human activity. Innovation is considered a way to add value, qualifying events when they present something new. Any actions that have the characteristic of novelty can be evaluated as innovative. Nowadays, the search for innovation gives rise to a series of discussions, in general because creativity is an illusion. This understanding can often be used as a rule, hence building the selfconsciousness.

The etymological meaning of the term innovation is from late Middle English: specifically, the Latin "innovatio", from the verb "innovare", used since the 18th century to indicate the sense of renewing. In its wide employment throughout history, innovation has referred to configurations of contents. Thus, the definitions found in the Oxford Dictionaries have the following meanings: firstly, the action or process of innovating; secondly, a new method, idea, product, etc. 
On the whole, it is the ability to renew, considering the development of techniques and technological evolution in the broad sense of the historical notion of innovation. In short, innovation itself is a method or object that depends on invention, on ideas. However, today, innovation is mainly a means or a process of commercial exploitation fundamental to economic growth. These conditions of innovation are linked to technological activities, conceptions, development, and the management of achievements according to the circumstances of the political, economic and social systems.

Although these "innovative" activities are elementary and come from a long list of achievements, we realize the situation between reality and imagination, leading us to the universe of images in building the visual culture. Moreover, the representations of a system, due to the influence of the cultural production, promote the innovation. A new form of standardized consumption, namely self-consciousness that is aimed at globalization, seeks fidelity to the demand for consumption habits that are surrounded by the configurations of the images.

The images transmit illusion as simulacra, creating the stimuli of consumption. There is a concern to ensure production for large-scale consumption and future generations. In this case, it is clear that immediate investments must be secured. Moreover, a market plan ensures the future of the public in today's production. The artifices of the images and their aesthetic values ideologize universal themes, and their rationale is based on the realization of collective consciousness and thus social importance. The notion of visual narratives - images - analyzing the consumer society is the invention, containing in it the reasons for the contemporary social reality.

\section{Acknowledgements}

This work was supported by Postdoctoral Research Fellowship PNPD/CAPES.

\section{References}

Descartes, R. (1911). The principles of philosophy. Translated by E. Haldane and G. Ross. Cambridge: Cambridge University Press.

Francastel, P. (1956). Art et technique aux XIXe et XXe siècles. Paris: Gallimard.

Habermas, J. (1970). Technology and science as ideology. In: Toward a rational society. Boston, MA: Beacon Press, 81-122.

----- (1995). The structural transformation of the public sphere. T. Burger and F. Lawrence (trans). Cambridge, MA: MIT Press.

(1984). The theory of communicative action. Vol. 1, T. McCarthy (trans.), Boston: Beacon Press.

Hegel, G. W. F. (1986). Vorlesungen über die Ästhetik. Frankfurt: Suhrkamp.

Houlgate, S. (2016). Hegel's aesthetics. The Stanford Encyclopedia of Philosophy, Edward N. Zalta (ed.). Retrieved from https://plato.stanford.edu/archives/spr2016/entries/hegel-aesthetics/

Lukács, G. (1972). Ästhetik. Vol. I,II, III, IV. Berlin: Luchterhand Verlag.

(1971). Class consciousness. In: History and class consciousness. R. Livingstone (trans.), Cambridge, MA: MIT Press, 46-82.

Marx, K. (2009). Das Kapital, Kritik der politischen Ökonomie. Köln: Anaconda Verlag.

Morin, E. (2007). Où va le monde ? Paris: Éditions de L’Herne. 
Ch. Wagner - Visual Narratives: Image and Cosciousnes of Social Reality

Thom, M. (2014). Ein Vergleich der Hegel-Kritik von Feuerbach und von Marx. Deutsche Zeitschrift für Philosophie, 31(6), 688-704. doi:10.1524/dzph.1983.31.6.688.

Van Gulick, R. (2017). Consciousness. The Stanford Encyclopedia of Philosophy. Edward N. Zalta (ed.). Retrieved from https://plato.stanford.edu/archives/sum2017/entries/consciousness/

Wagner, C. (2014). Esthétique: l'image contemporaine et l'analyse du concept de l'innovation. Saarbrücken: Paf. 